\section{Waterton's Wourali}

To the Editor:

I read with great interest Dr. J.R. Maltby's paper on Charles Waterton' in which he explains the link between the 'Yorkshire Squire' and the Waterton Lakes National Park in Southern Alberta, For anaesthetists the link is more tangible through Waterton's first description of the reversible effects of wourali (curare) on a large mammal in 1814 and the first use of curare in anaesthesia by Griffith and Johnson in 1942 in Montreal. Another link was forged when Dr. Maltby became a prime mover in encouraging the Yorkshire Society of Anaesthetists to celebrate the bicentenary of Waterton's birth by holding a symposium at Walton Hall, Wakefield, in June 1982. Proceedings of this Symposium will be published in the British Journal of Anaesthesia.

It was also at Dr. Maltby's suggestion that we obtained, from Wakefield Museum, specimens of some of the original crude wourali that Waterton obtained from the Macusi Indians, and subjected it to chemical analysis and bioassay. ${ }^{2}$

Briefly, an aqueous solution of the crude woural was prepared with acid extraction and administered to a rat diaphragm-phrenic nerve preparation. A reversible neuromuscular inhibition of twitch resulted. In a bioassay in which the wourali solution was compared with commercial d-tubocurarine it was found that the crude solid wourali still contained a potency equivalent to 2.44 per cent d-tubocurarine by weight.

Chemical analysis was performed using infrared spectroscopy, thin layer chromatography and high performance liquid chromatography. The aqueous extract of Waterton's wourali was compared with other curares including commercial d-tubocurarine (Wellcome) and Peruvian crude curare (supplied by Wellcome). D-tubocurarine and chondrocurarine were demonstrated in an extract of the Peruvian crude curare but neither alkaloid was found in Waterton's wourali.

The absence of $d$-tubocurarine came as a surprise although on more careful re-reading of McIntyre's monograph on Curare ${ }^{3}$ we recognized that the Menispermaceous curares are found mainly in the upper Amazonian regions of Brazil and Peru whereas the Loganiaceous curares are mainly from Guyana, Venezuela and Colombia. Unlike modern crude curare which is often of mixed source, having been traded hundreds of miles from the place of origin, Waterton obtained his wourali directly from the Macusi Indians in south western Guyana.

We concluded that Waterton's wourali did not derive from the Menispermaceae, which include Chondodendron tomentosum and produce isoquinoline alkaloids, but was most likely to be from the Loganiaceae, including Strychnos toxifera, and produce toxiferine alkaloids. Waterton's wourali almost certainly owes its neuromuscular properties to the presence of alkaloids of the toxiferine series but, pharmacologically, the toxiferine alkaloids are impossible to distinguish from the isoquinoline alkaloids.

\section{F. Richard Ellis, PHD, FFARCS}

University Department of Anaesthesia

St. James' University Hospital

Leeds, England

REFERENCES

1 Maltby JR. Charles Waterton (17B2-1865): Curare and a Canadian National Park. Can Anaesth Soc J 1982; 29: 195-202.

2 Cook J, Cuwood A, Crossley A, Elis FR, Wourali; Analysis and Bioassay, $\mathrm{Br} \mathrm{J}$ Anaesth (in press)

3 McIntyre, $A R$. Curare, lts History, Nature and Clinical Use. University of Chicago Press (1947). 